\title{
The Use of Teaching Aids in the Teaching of French as a Foreign Language in Nigeria
}

\author{
Iluromi P. Babatunde \\ Department of French, Federal College of Education, Nigeria
}

Copyright $\bigcirc 2016$ by authors, all rights reserved. Authors agree that this article remains permanently open access under the terms of the Creative Commons Attribution License 4.0 International License

\begin{abstract}
Language is said to be the fulcrum of human development as well as instruments for unification of people and nations. This probably explains why Nigeria declared French as the nation's second official language. However, the teaching of French language cannot be effective without the use of teaching aids. The use of teaching aids in the teaching process is imperative. Teaching aids help to overcome the French language barrier and get right to the heart of meaning. This can be only possible through the use of relevant teaching aids, conducive classroom environment, class control and good medium of communication between teachers and students. The aim of this paper is to encourage teachers not to wait for the ideal materials to be made available, but rather to investigate materials presently available, make substitutes for non-available materials and use them to their fullest extent. It therefore examines how to choose or select, prepare and effectively handle teaching aids. It concluded that Nigerian schools administration should make provisions for teaching aids so that teachers can enhance effective teaching of French in order for Nigeria to interact effectively with francophone countries locally and internationally.
\end{abstract}

Keywords Audio, Audio-visual, Non-printed Materials Printed Material, Visual

\section{Introduction}

The French language is a foreign language in Nigeria and as such, it is encountering a lot of problems among which is the problem of inadequate teaching aids.

The success of a foreign language course depends not only on the quality of the basic programme but also on the flexibility with which the teacher implements and supplements existing teaching materials of that programme.

Van Zyl [1], Adepoju and Odewusi [2] agree that that if used appropriately and in the right place, teaching aids contribute to purposeful teaching.
The production of teaching and learning materials, the storage, retrieval and dissemination is part of a wide discipline called educational technology.

Dada (1996) quoted in Ogunlade [3] defined educational technology as the whole range of equipment and modern facilities, which accelerates the teaching and learning process in institutions.

The development of educational technology in Nigeria could be dated back to the colonial and early post-independence era [3]

Now, in Nigeria, educational technology is a recognized discipline which helps in the facilitation of learning through the systematic identification, development, organization and utilization of teaching aids.

Teaching aids are materials that are used to complement teaching and improve the teaching-learning process in the classroom. Teaching in the classroom depends on the teaching materials, conducive classroom environment, class control and good medium of communication between teachers and students. For a teacher to achieve his goal, he has to make use of all of the above; without which, teaching cannot be completed.

Teaching aids are physical materials used to illustrate topics and make teaching more meaningful and explicit. They are also known as instructional materials. They help in bringing the world into the classroom and make learning easier. They are used to complement teaching and to enhance teaching and learning in the classroom.

\section{Types of Teaching Aids}

We have basically two types of teaching aids: printed materials and non-printed materials.

\section{A. Printed Materials}

Printed materials are regarded as traditional tools of learning and instruction in any formal education system. Examples are textbooks, workbooks, educational journals, magazines, picture books and a host of others. 


\section{B. Non-printed Materials}

The non-printed materials are called software and hardware and are also classified into sub-groups which are:

Visual aids which encompass a lot of things we can use in our classroom, (e.g., pictures, charts, tables and real objects).

Audio aids are materials that cannot be seen but can be heard, (e.g., radio programmes, audio recordings, songs, stories).Audio-visual aids are materials which can show still pictures or motion pictures and can also give sound to describe what is been illustrated or they provide audible and visible information. (e.g., television, video, movies projectors).

\section{Implementing and Supplementing Existing Teaching Materials}

Most teaching aids are available commercially but at some point, however, the teacher usually finds it desirable to prepare supplementary materials. These materials can usually be made rapidly and at a reduced cost. One way of producing them is through improvisation. Improvisation according to Ayantola [2] is the use of locally made materials instead of manufactured one for demonstration of instruction.

\section{Criteria for Selecting Teaching Materials}

Ayantola [2] argued that the following criteria should be taken into account while selecting teaching materials:

- Accuracy of timeliness of information and illustrations.

- Appropriateness in terms of objectives and maturity of students.

- Appropriate use of exposition, graphs and other means of presentation.

- Content free of bias or stereotypes. - Quality of design, clarity of presentation and effective use of illustration.

- Reasonable amount of time and effort for teachers and students to use.

- Usefulness of related manuals or supporting materials. - Enough variety of materials to meet individual's needs.

\section{Preparing Supplementary Teaching Aids}

\section{A. Posters and Charts}

Posters and charts are among the widely used supplementary teaching aids in foreign language [5]. They are usually made of tag board, available from any arts and crafts supply store. This heavy cardboard can be supported on the ledge of the chalkboard or propped on a desk. It comes in a variety of bright colours. Lines should be broad enough and words large enough to be easily visible from the back of the classroom. Permanent markers are the most appropriate writing tools on poster and the darker the colours, the more they are visible.

\section{B. Cue Cards}

Cue cards can be used by both students and teachers. They range in size from $3 \times 5$ to $8 \frac{1}{2} \times 11$ - occasionally somewhat larger. Cue cards which are to be distributed to the students should be marked on both sides. Ordinary $3 \times 5$ index cards may be used for single digit numbers and simple line drawings. The $4 \times 6$ are more suitable for longer numbers or words. Larger cards may be used for mounting magazine pictures. For example, the teacher may have distributed index cards with numbers to students. He might ask Paul to hold up his card and then ask another student Quel age a Paul? The student is to tell Paul's age according to the card he is holding. Another version is to distribute index cards with letters symbolizing French cities (P- Paris, M-Marseille, B-Bordeaux etc) to students. Then the teacher asks a student to hold up his card and then asks another student Où habiteil? The student is to tell where the one holding the card lives.

\section{Flannel Board}

The teacher can make an inexpensive flannel board by getting a piece of plywood, heavy cardboard, artist's canvas and tack or tape a piece of dark flannel to it. Pictures or cut-outs can be displayed on the flannel board if you glue a small piece of flocking paper, sandpaper, or flannel to the back of the picture or cutout. Cutouts may also be made from Pellon (a material used in sewing, available in any yards goods store) or from desk notebooks, words may be written on the Pellon or notebooks by using felt pens.

\section{Magnetic Board}

Many of the newer whiteboards are magnetized and can be used as magnetic boards. One can be made by cutting a piece of light-weight sheet metal to a size of 24" x 24" . Masking tape can be used to blind the sharp edges. Magazine pictures and light -weight cue cards are held to the board by magnets.

\section{E. Pockets Charts}

A pocket chart may be made very simply by taping the bottom and side hedges of four to five narrow strips of oaktag to a larger sheet of oaktag which has been mounted on heavy cardboard or to a bulletin board. These strips form pockets in which flash cards, cue cards, or pictures can be inserted.

\section{F. Drawings}

They say a picture is worth a thousand words, and nowhere is that more true than in the FFL classroom. The 
teacher need not be an artist before drawing. Simple line drawings are often more effective than detailed sketches, because the main function of drawings is to elicit speech, not to distract the eye.

Students remember symbols very easily, once their significance has been explained in French language. The teacher may say that an inverted $\mathrm{V}$ represents a roof. Then he could design a building by appending symbols or letters to the $\mathrm{V}$ roof.

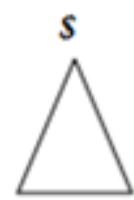

Bank

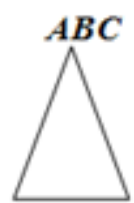

School

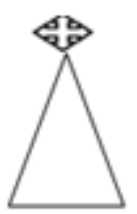

Church

\section{G. Dimensional Materials}

These are real objects or materials having length, breadth and depth. They also include three- dimensional materials such as models or puppets. They provide concrete and realistic experience for the students and encourage them to think of things outside their environment. Learning takes place through the students' five senses. Those materials can be sourced from our immediate environment.

\section{H. Recordings}

The recordings may consist of songs, folktales, interviews, dialogues, but often the available recordings that accompany almost all of the available French language programmes do not completely meet the needs of the students. The teacher can therefore edit an appropriate lesson tape for the language laboratory or classroom by using two tape recorders, or a record player and a tape recorder. The teacher may duplicate the commercial recording in the desired sequence on a new tape. He may then add his own instructions between exercises using a microphone.

\section{Media Broadcast}

Radio and television help in disseminating volumes of education information to people. In most parts of Nigeria, it is possible to receive French programmes from RFI and TV 5 or other neighbouring countries' media such as Benin, Niger, Cameroon, and Chad Republic. Some broadcasts are especially prepared for French language users and are broadcast on FM radio stations at regular times. Eko FM (89.75 FM) a public radio station of Lagos state is one example. So the teacher can tape those broadcasts and bring them to the classroom. In addition, the cable channel TV 5 has some instructional programmes which can also be taped and used in the classroom.

\section{J. Recording Tests and Homemade Exercises}

Several steps must be followed to record original materials. First of all, a script must be prepared in advance. If the teacher does not possess native fluency in French, it is advisable to have a colleague read over the script and make necessary changes. Secondly, ample time must be allowed for the recording session; it usually takes two and half to three hours to make an hour recording of tape. Moreover it is advisable to listen to the entire recording at the end of the session so that if necessary, parts can be recorded at once.

\section{K. Scheduling Audio-visual Equipment}

Some schools have a variety of audio-visual equipment but sometimes it is necessary to schedule the use of equipment in advance in order to avoid clashes with another language department.

\section{Preparing to Meet Problems}

Sometimes, the carefully scheduled piece of equipment arrives on time, but then cannot be used due to electric power failure or because one element of the equipment is not functioning well. For instance, it is wise to keep a prong adapter, an extension cord and an empty reel in the desk in case one equipment needs them.

\section{Enlisting the Help of Students or Colleagues}

The teacher who is uncomfortable with complex equipment can usually find a student who can run the piece of equipment he wishes to use. Perhaps a colleague in another department likes electronics. In exchange for his effort, the French language teacher would render him another service such as translating a text for him. Sometimes students themselves are willing to make visual aids. Perhaps a lettering class in art could be persuaded, with the consent of the teacher, to prepare a chart of grammar generalization.

When you use visual aids to communicate with your students, you overcome the language barrier and get right to the heart of meaning. When teaching concrete vocabulary, visual aids like picture dictionaries are essential, but don't stop there. You can use visual aids to teach grammatical concepts as well. And by giving my students those visuals, they have a concrete picture of an abstract concept. Not only does this improve our communication, it makes them more successful learners and more motivated students. Because we often struggle with a language barrier, using visual aids makes communication less dependent on words that they might not understand.

\section{Conclusions}

Effective teaching does not mean waiting for the ideal materials to be made available. It means investigating materials presently available, making substitutes for non-available materials and using them to their fullest extent. 


\section{REFERENCES}

[1] Van Zyl. P. J .Teaching and learning aids in the lesson structure. Onderwystegnologie in universitere;verband, Afrikaans University [internet] 1977. [Cited 3 May 2014]; 21(3): 876-880. Available from:http://georgeyonge.net/sites/ georgeyonge.net/files/Guide_ch7.pdf

[2] Adepoju H, Odewusi. B. Adult education studies. 2nd ed. Osogbo, Nigeria: Alpha; 2009.

[3] Ayantola A.N. Effective utilization of teaching aids in enhancing teaching and learning of social science based subjects. In: OSSCE, editor. The College Review. Ila-Orangun 2007.vol. 14, p. 173-178.

[4] Ogunlade O. O. Educational technology, Osogbo: Everlasting, 2007. ch. 1. , pp. 123-135.

[5] Modern language classroom techniques. USA, NC: Harcourt Brace Jonovitch Inc. 1972. 